\title{
Ideas for Improving Peer Review
}

Jorge Mira-Perez

Citation: Physics Today 56, 11, 11 (2003); doi: 10.1063/1.1634515

View online: https://doi.org/10.1063/1.1634515

View Table of Contents: https://physicstoday.scitation.org/toc/pto/56/11

Published by the American Institute of Physics

\section{ARTICLES YOU MAY BE INTERESTED IN}

Domingo de Soto, early dynamics theorist

Physics Today 62, 9 (2009); https://doi.org/10.1063/1.3074244

Determining Longitude: A Brief History

Physics Today 58, 15 (2005); https://doi.org/10.1063/1.2138398

Echegaray-Fiscal Scientist and More

Physics Today 53, 76 (2000); https://doi.org/10.1063/1.1306382

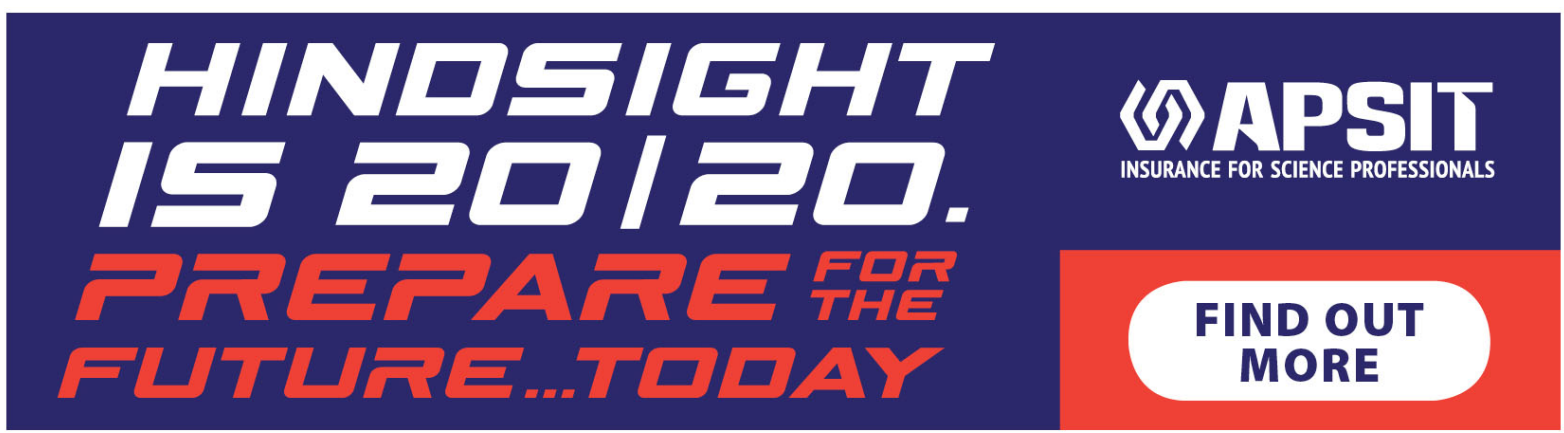


eventually lead to commercial applications. The industrial partner may choose to manufacture the product in the FSU country or in the US, but royalties are sent to the FSU institute. As of October 2002, 13 IPP products have entered the world market and have generated annual sales of more than $\$ 27$ million.

Ken Touryan (ken_touryan@nrel.gov) National Renewable Energy Laboratory Golden, Colorado

\section{Nobel Work Done at Francis Bitter Lab}

n their article "A Topological Look at the Quantum Hall Effect" (PHYSICS TODAY, August 2003, page 38), Joseph E. Avron, Daniel Osadchy, and Ruedi Seiler describe Klaus von Klitzing's discovery of the integer quantum Hall effect. That work led to his winning the Nobel Prize in Physics in 1985. The authors correctly identify the Grenoble High Magnetic Field Laboratory in France as the facility at which the initial discovery was made. They subsequently write about how Horst Stormer, Daniel Tsui, and "coworkers at AT\&T Bell Laboratories" found evidence of a fractional quantum Hall effect. Stormer and Tsui, along with the theorist Robert Laughlin, received the 1998 Nobel Prize in Physics for that work. However, omitted from the discussion was the fact that the experiments leading to the prize-winning results were performed at what was then the MIT Francis Bitter National Magnet Laboratory. A plaque acknowledging that accomplishment hangs in the lobby of the laboratory.

Lawrence G. Rubin (lrubin@mit.edu) MIT Francis Bitter Magnet Laboratory Cambridge, Massachusetts

\section{Ideas for Improving Peer Review}

$\triangle$ uthorship of articles in scientific Ajournals is a key parameter in career evaluations of science professionals, and the health of that parameter clearly depends on the peer review process. Unfortunately, that process does suffer cases of misconduct, usually related to conflicts between individuals or groups or to direct malicious interference. In my view, journals need to recognize their responsibility as custodians of honesty and authorship.

Sometimes it seems that authors' names are subject to more critical review than their work. To avoid that possibility, anonymous review in which the authors are not identified should perhaps become a much wider practice. Transparency and efficiency might also be improved if referees' comments were published online. Excessive delay in the review process or the transfer of a submitted paper from one journal to another in the same publishing group without retaining the original submission dates has, on occasion, enabled basically plagiaristic papers to be published before the work they plagiarized.

Another problematic area in the process is citations: The right to be cited must be ensured. To help accomplish that, journals could include a comments section in which authors would be able to call attention to papers that do not properly cite their relevant work.

Jorge Mira-Perez (fajmirap@usc.es Universidade de Santiago de Compostela Santiago de Compostela, Spain

\section{COMPONENTS \& SYSTEMS FOR NANOTUBE oR NANOWIRE SYNTHESTS}

COMPONENTS AND SYSTEMS THAT SOLVE PROBLEMS IN
SYNTHESIS OF NANOSTRUCTURES BY THE CVD METHOD

\section{INEXPENSIVE GOMPONENIS AND KITS FOR:}

- Leali-proof gas seals for quartz tubes

-2. Fast loading/unloading of substrates

Safoty lit for detection of gas leaks

\section{Custom Systems}

Built to Spec!

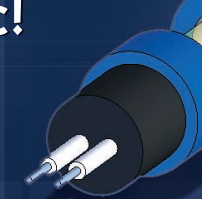

\section{QUABANTEED TO WORK! Gall toll free in the U.S.A. 1-800-747-1696}

Atomate Corporation

711 Bond Avenue, Santa Barbara, CA 93103 USA Phone: (805) 963-1779 Fax: (805) 435-1951

Web: www.atomate.com Email: info@atomate.com

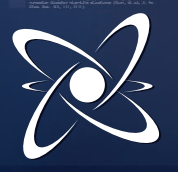

